\title{
RELATIONSHIPS BETWEEN ACADEMIC ENVIRONMENT, PEER RELATIONSHIP, TIME MANAGEMENT AND PSYCHOLOGICAL WELL-BEING
}

\author{
${ }^{1}$ HANINA HALIMATUSSAIDIYAH HAMSAN, ${ }^{2}$ LOH PEI YEE \\ ${ }^{1,2}$ Fakulty of Human Ecology, Universiti Putra Malaysia
}

\begin{abstract}
The purpose of this study was to determine the relationship between academic environment, peer relationship, time management and psychological well-being among final year students in Universiti Putra Malaysia. The study also determines the level of each stressor, and the relationship between each independent variable (academic environment, peer relationship, time management) and dependent variable (psychological well-being) among final year students. Besides, this study also Respondents were 333 final year students who study at Faculty of Human Ecology (FEM), Faculty of Economic and Management (FEP), and Faculty of Engineering (FK). They were selected based on Proportionate stratified random sampling. A selfadministered questionnaire was used as a tool for data collection. University Environment Scale (Gloria and Karpius, 1996), Index of Peer Relationship (Walter W. Hudson, 1992), The Time Management Behavior Scale (Macan, 1990), and were used to measure academic environment, peer relationship, time management respectively. Dependent variable which was psychological well-being was measured by using Depression Anxiety Stress Scale 21 (DASS 21) which developed by Lovibond and Lovibond's in year 1995. The results showed that majority of student had moderate level of perception to academic environment, setting goal and priorities, planning and scheduling, perceived control over time, preference for disorganization, overall time management behaviour and moderate level on depression. Besides, most of majority student have low peer relationship, extremely severe anxiety, and had normal stress. There is significant correlation between academic environment and depression $\left(r=0.149^{* *}\right)$. Respectively, peer relationship was found have significant relationship with the psychological well-being subscales: depression $\left(r=-0.468^{* * *}\right)$, anxiety $\left(r=0.374^{* * *}\right)$, and stress $\left(r=0.441^{* * *}\right)$. Time management also
\end{abstract}


Hanina Halimatussaidiyah Hamsan; R elationships between academic environment, peer relationship, time management and psychological well-being

have significant relationship between depression $\left(r=-0.189^{* * *}\right)$, anxiety $\left(r=0.207^{* * *}\right)$, and stress $\left(r=0.197^{* * *}\right)$. Academic environment have no significant relationship between anxiety $(p>0.05)$ and stress $(p>0.05)$. The study concluded that peer relationship (PR), and time management (TM) have significant predictor towards depression $\left(B_{P R}=0.458\right.$; $\left.B_{T M}=0.233\right)$, anxiety $\left(B_{P R}=0.407 ; B_{T M}=0.209\right)$, and stress $\left(B_{P R}=0.463\right.$; $B_{T M}=0.212$ ) among final year students. Among the two predictors, peer relationship was found have most significant towards depression, anxiety, and stress of final year student, followed by time management. Study suggested that university should develop intention program, appropriate counselling service to student. Besides, student should learn good time management skills and habit in order to develop positive psychological well-being. Future study are encourage to include more possible sources of student psychological well-being, add more size of sample and apply different data collection tools for deeper investigation.

Keyword : Peer Relationthips, Time Management, Psychological WellBeing

\section{INTRODUCTION}

Psychological well-being, broadly can be defined as happiness, life-satisfaction, and selfgrowth, represents one of the most important aspect of efficient psychological functioning (Vallerand, 2012). According to Bradburn in year 1969, psychological well-being can be measure in two aspect which are positive aspect (happiness, life satisfaction and competency) and also negative aspect (depression, anxiety, and stress).

Over five decades ago, the study or literature about psychological well-being has progressed speedily. Social scientists and psychologists have given a lot of concern and try their best in understanding and exposition of the factor that giving effect on psychological well-being. Psychological well-being means that how people assess their lives. On the other words, psychological wellbeing refers to a person's own assessment of their satisfaction with life (Diener, 1997). Mental health researches often give concern on negative emotion such as depression, anxiety and stress. But, nowadays, there is much literature on examine positive as well as negative aspects of psychological well-being.

Psychological well-being also can defined as the sickness or healthy of individual as a result of an internal part of a person such as individual thoughts, sense, sentiment, understanding and 
perceptions. Negative life experience and events of a person have significant related with depression, stress and anxiety (World Health Organization, 2012). The ability of a student to cope or adjust his or her psychological or internal emotion is important in order to face new challenges. When a person fairly cope or adjust their internal emotion when solve the problem or challenges effectively can become a serious problem especially on their psychological health.

A National College Health Assessment (NCHA) survey which conduct by American College Health Association (ACHA) of 28,000 Western's students from 44 colleges and universities by using random sampling is used to assess student's health status and behavior, including depression, anxiety, and stress in the previous study year. Based on their findings in year 2012, 31.6\% have felt depressed that it was difficult to do things, $23.7 \%$ feeling very sad with preceding two weeks; $51.3 \%$ reported having an anxiety disorder in anytime within last 12 months; and 30.5 percent reported that stress has negatively impacted their academic performance (Reference Group Data Report Spring, 2011).

Similarly, the 2012 National Survey of Counseling Center Directors (NSCCD) on a 228 campuses reported that 37.4 percent of counseling center clients had severe psychological problem, and close to 6 percent had serious impairments that they could not remain in college, or could do so only with extensive psychological help. The common psychological disorders were depression, anxiety, suicidal ideation, eating disorders and self-injury.

Psychological well-being of a student especially final year students can be affected by academic environment or campus climate. University life is a significant period for an adolescent or young adult explores themselves and gain more experiences before a person turn himself to the working environment. So, academic environment is important place in order student can explore themselves and learn new knowledge. Sense of belonging or feeling of being support such as teacher, lecturer, university staff and etc. also important to a student and will affect a student development in academic environment (Ryzin, Gravely \&Roseth, 2009). Students who feel supportive, comfortable, familiar and warm in academic environment will have more positive aspect of psychological well-being compare to others (Moos, 2003).

More so, another component part of is peer relationship, has been found to be significantly related to psychological well-being of a student (Zalaquett, 2005; Wycoff, 1996; Friedman, Tripton, \& Linn, 2000, Preiffer, 2001; Stanton-Salazar 
Hanina Halimatussaidiyah Hamsan; R elationships between academic environment, peer relationship, time management and psychological well-being

\&Spina, 2005). Interpersonal relationship of an individual is one of the components of psychological well-being. When people have good interpersonal relationship, he or she also will have better psychological well-being. Peers are important source of social support which contributes to student's well-being (Stanton-Salazar \&Spina, 2005). Some of the studies stressed that peer relationship benefit to psychological well-being of students or moderated or reduced the negative aspect of psychological well-being, while others opined that peer relationship have mediated or increase depression, anxiety and stress among students (Reis, Sheldon, Gable, Roscoe, \& Ryan, 2000; Ueno, 2005). In line with above overview, this present study is conduct in order to examine the relationship between peer relationship and psychological wellbeing.

Besides, time management of a student also has significant relationship will psychological wellbeing. A person who have planning and clearly understanding what so he want to do, what they need to do and so on is a person who can manage their time effectively (Laurie, 2012). People who have higher in perceive control over time will have higher performance in academic and psychological well-being and also emotional adjustment (Macan, Shahani, Dipboye\& Phillips, 1990).
Negative aspect of psychological well-being such as depression, anxiety, and stress can be reduce if an individual have good time management by being more in control of their time and being more effectiveness. People who are good time management skill will have more quality time to relax and enjoy their life (Jones, 2002).

In generally, this present study would like to determine relationships between academic environment, peer relationship, time management and psychological well-being among final year students Universiti Putra Malaysia, Serdang, Selangor.

\subsection{Statement of problem}

Psychological well-being has always been studies of educator and researchers for a long time. Relationship between academic environments, peer relationship, time management and psychological wellbeing have been studied but, the relationships among these all variables have not yield consistent results. For example, Moos (2003); Ryan and Deci (2000) have studied about relationship between academic environment and psychological well-being. Besides, Wycoff (1996); Friedman; Tipton and Linn (2000); Preiffer (2001); StantonSalazar and Spina (2005); Ueno (2005) and also Zalaquett (2005) have examined between peer relationship psychological wellbeing. Last but not least, Macan, 
Shahani, Dipboye and Phillips in year 1990; Britton and Tesser in year 1991 and Jones in year 2002 have investigated between time management and psychological wellbeing. However, all above literature did not conclude all the variables in a single research. Hence, the relationship between these all variable need further investigation.

Low self-esteem, low satisfactions, anger, depression and anxiety were some of the psychological factors which can observe among students. Depression can be characterized by sadness, loss of interest, less focusing on thing, loss self-worth, affect sleep quality, feeling of tiredness. It is a common mental disorder and affects individual's ability in doing their work, at school and family. In globally, more than 350 million of people are affected by depression. Depression can become a serious health condition if it didn't cope by the person (World Health Organization, 2012). On average about 1 in 20 people having depression disorder in year 2011 which have conducted in 17 countries by World Mental Health Survey (Marcus, Yasamy, Ommeren, Chisholm \&Saxena, 2012).

Depression, anxiety and stress in young adults have rank as the most common health problem by college centers and it also a growing to public concern (World Health Organization, 2012). According research which have conduct by Wong and Lua in year 2011, a research which have done by World Health Organization in year 2001 showed that about 150 million people suffer themselves from depression and anxiety. Besides, according to study of WHO organization, around one million people think negatively and suicide in every year. These numbers are increasing nowadays and become a serious problem towards Malaysia.

The rising number of student in negative aspect of psychological well-being such as depression, anxiety, and stress also have given effect on eating disorders, substance abuse and self-injury of a student which have founded by National Survey of Counseling Center Directors (NSCCD). Thus, in order to respond proactively to negative aspect of psychological well-being, it is important to understand and assess the academic environment, peer relationship and time management of UPM students.

\subsection{Significant of study}

University life is a significant period for an adolescent or young adult explores themselves and gain more experiences before a person turn himself to the working environment. Besides, university life also is a period that can let young adult learn more, try more and learn from mistake. So, their well-being in this transition period may bring effect 
Hanina Halimatussaidiyah Hamsan; R elationships between academic environment, peer relationship, time management and psychological well-being

to their future life. Student, especially to those who are final year is more busy when compare to others. They have a lot of workload, most if not all of them need to decide their future career, and some of them may busy in doing Final Year Project (FYP) which have given a big challenging and felt stressful in his or her study life. Hence, this study appears as an evident that contributes in field of study of Bachelor Science (Human Development and Management). This study has empirical data of result in order to provide guideline for researcher for the purpose of academic and research.

Although there are a lot of existing journal, book and knowledge regarding the contributing factor to students' psychological well-being, but most of them were done outside Malaysia (example: "Stress level of university student" which study by Sayner in year 2006; Perceived control of time: time management and personal effectiveness at work which study by Brown in year 2009; and The effects of friendship networks on adolescent depressive symptoms by Ueno in year 2004). Our country is lack of the studies on this topic. Therefore, this study can be used as literature review and important information to other. Besides, this study can be significant related to any person such as academic community, university psychologists, educator, as well as other student.
It is also can be significant related to any other university in Malaysia. This study can be used in a form practical. Result from this study can be used as important information in order to upgrade and improve the point of view of those universities which have the power to make an impact on student psychological well-being and benefit student community, such as develop some activities and programs. For example, intervention program can be organize by UPM in order to prevent negative aspect of psychological well-being happened among university students.

This study also can be vital to a nation consequently. Having good psychological well-being condition is one of the important aspects of student development and it may affect his or her social competency and respectively the society as whole. Gradually, finding from this study can provide fundamental information for the next generation to study in depth on this topic.

\subsection{Student's psychological well- being}

There was no much article or research examined psychological well-being among university students and how the experience may affect a student's psychological well-being (Bowman, 2010). However, psychological well-being could be defined as a combination of determine emotional, cognitive, 
behavioral and interpersonal virtues (Wissing\& Van Eeden, 2003; Smith, 2008). Psychological well-being also could broadly define as happiness, life satisfaction, and self-growth; represent one of the most important aspects of efficient psychological functioning (Vallerand, 2012).

According to Bradburn on his Affect Balance Scale (ABS) in year 1969, he found that psychological well-being basically could be divided into two affects, which were positive affect and negative affect. Happiness, life satisfaction and competency were including in positive affect. However, negative affect could be measured as depression, anxiety, and stress mood. A positive psychological wellbeing with happiness could be achieved when it has balance between positive and negative affect (Ryan \&Deci, 2001). This important aspects which were positive and negative affect should be included in psychological well-being have agreed by researchers who were in the field of psychological well-being (Boey\& Chiu, 1998; Tang, 2008).

Psychological well-being defined as a sense of emotional health which can prove by high selfesteem and positive relationships with others, and a lack of anxiety, depression, and deviant behavior. According to the study which have done by Ryzin, Gravely and Roseth (2009) reported that sense of autonomy, environmental mastery, personal growth, positive relationship with others, purpose in life, self-acceptance and belongingness and engagement in school has contributors to an individual sense of well-being. In this article of Ryzin, Gravely and Roseth (2009) also have stated that people who have positive psychological adjustment such as self-esteem, self-worth and so on will have positive psychology feeling and avoid from mental illness.

Negative pattern of thinking have contributed feeling depression towards a person (Beck, 1967). Depression could be characterized by sadness, loss of interest, less focusing on thing, loss self-worth, affect sleep quality, feeling of tiredness. It was a common mental disorder and affects individual's ability in doing their work, at school and family (World Health Organization, 2012). In globally, more than 350 million of people were affected by depression. Depression can become a serious health condition if it didn't cope by the person.

One of the elements including in psychological well-being was stress. Human's experience in stress was different from each other. Major life event, trouble in daily life, and changes in life have been related with stress (Pfeiffer, 2001). Stress has become one of the serious issues which could give effect on university student's life. Its effects 
Hanina Halimatussaidiyah Hamsan; R elationships between academic environment, peer relationship, time management and psychological well-being

have given impact on student social, academic and mental health. Individuals' behaviors, communication and efficiency have affected by negative emotional such as stress in educational environment (Sayner, 2006). For example, people who were under pressure will tried to become smoker or take up smoking, excessive in eating, unhealthy weight gain and also take alcohol and drug. Stress may occur because of a person failed in psychological adjustment.

Besides, stress could have positive and negative effect to a person if didn't manage it well (Stevenson \& Harper, 2006). A person respond toward stress depend on his or her perception regarding an event whether the event was assessed as a challenge or a threat (Lazarus \&Folkman, 1984). Challenge could be stimulated as positive outcome such as motivation and if a person feels an event was threat, it could result feeling anxiety, stress, depression and social dysfunction.

\subsection{Relationship between academic environment and psychological well-being}

Academic environment also could be described as campus climate. Campus climate could be defined as the perceptions of students towards their university or college's response to ethnicity, race, and diversity on university. The perception could be either positive or negative perceptions of students toward their university environment. The result of cultures, values, and traditions which support by the community of campus such as faculty, staff, and students were the result of campus climate (Garcia, 2005)

According to research on social context and socio-ecological perspective which have done by Moos in year 2003, it have stated that psychological well-being have significant intimately relationship with social climate of an environment. Social climate which states by Moos in year 2003 was means that each social environment such as classroom, a family, or a taskoriented group and society have unique personality and may be give some coherence or different between each other. For example, a person will feel more supportive, comfortable, familiar and warm in some social environment when compare to other environment. Moreover, different people with different characteristics have their own suitable environments such as a people who are self-directed and task oriented will more comfortable and enjoy in the environments which encourage self-direction and task orientation when compared to others. Moos also has states that a wide range of quality of life areas, including psychological well-being, personal achievement, self- 
understanding, decision making and so on have been influence by social climate.

Some of the study found that student motivation, engagement and academic achievement could be encouraged by high-autonomy learning situation. For example, a school which provides a high degree of choice and self-direction could encourage student to do the decision and take responsible to the decision. It could encourage and give motivation to a student when the decision or choices are correct (Ryan \&Grolnick, 1986; Vansteenkiste et al., 2004; Ryzin, Gravely \&Roseth, 2009). However, if a student was control by teacher or lecturer, his or her perceptions towards autonomy have reduced (Grolnick\& Ryan, 1987; Ryzin, Gravely \&Roseth, 2009). So the support by university, teacher, lecturer, and academic staff was plays an important role to the student in order to build autonomy and sense of belonging to success in school.

Besides, autonomy of a student in academic also have been found have relationship with psychological well-being (Ryan \&Deci, 2000). Students who have autonomy in their academic will have positive relationship with positive coping strategies. However, students who have lower academic autonomy have higher level of negative coping strategic and feeling anxiety (Ryan \&
Connell, 1989; Ryzin, Gravely \&Roseth, 2009). It was important that university give opportunity to a student to practice, experience and increasing the amount of choices such as student have autonomy in choosing his courses very semester, the society that the want to join, and so on could contribute to adolescent psychological well-being and become more success in their life.

Sense of belonging or feeling of being support also important to a student and will affected a student development in academic environment. Students who have support from friends, teacher, lecturer, academic staff and university staff have been found to have more success in academic, have motivation and also have better feeling. Moreover, supportive by teachers or lecturer was also important to students. It can build up students' prosocial behavior, motivation, participation, interest in school and also academic achievement (Roeser\&Eccles, 1998; Roeser et al., 1998; Ryan \&Grolnick, 1986; Ryan et al., 1994; Wentzel, 1994, 1997, 1998; Ryzin, Gravely \&Roseth, 2009). When students feel him or her being support by people in academic environment and have sense of belonging, he was easier and success in adjusting himself toward problem that he faced. So, the level of psychological problem such as depressive, anxiety, and stress were lower compared to 
Hanina Halimatussaidiyah Hamsan; R elationships between academic environment, peer relationship, time management and psychological well-being

others who are alone or didn't have sense of belonging in academic environment.

Class size or classroom also has given impact on psychological well-being of students. According to the study of Blatchford, Bassett, Goldstein and Martin in year 2003, a large teaching group of student present problem like inattentiveness and off-task behavior. Teachers were difficulty in communicated with all students. Compare to large teaching group of students, a smaller group of student in a class have given benefit to individualize instruction among student. Teachers could increase their monitoring of student learning and behavior in a small size group of student compare to large group of student in a class. Besides, teacher has chance in immediate individualized teaching in small class size of student. Teacher also could be easily interacted with student and understand the need of student and know more the ability of each student (Gross, 2009). Student in smaller group will have sense of belonging from teacher or lecturer. Sense of belonging was important and it contributes positive psychological well-being of students (Ryzin, Gravely \&Roseth, 2009).

\subsection{Relationship between peer relationship and psychological well-being}

Peer refers to an individual or a group of people, who interact with each other, share friendship, hang out, talk to each other and do activities together (Brown, 2009). Peers were important source of social support which contributes to adolescents' well-being (StantonSalazar \&Spina, 2005). According to the American Academy of Child and Adolescent Psychiatry (2012), peer relationship has been recognized as among the most influence factors during the period of late adolescent and young adult. On the other word means that peer group plays a significant role in the socialization on the period of adolescent. Many psychologists, sociologists, economists, social and behavioral scientists, and medical researchers have studied the reflecting of important of peers in adolescent life (Larson \& Richards, 1991; Robert \& Clea, 2008). During this particular time, the frequency spends with parent or families were low compared to the time that spends with peer. Hence, social support among friends was very important.

Many research have showed that the important of social support in a life of successful student (Zalaquett, 2005; Wycoff, 1996; Friedman, Tipton, \& Linn, 2000, Preiffer, 2001). Social support has been found important in a student lives. Social supports consist of meaning full interaction between people. Student could use social 
support in order to help them get out or change personal perspectives from the negative aspect of psychological well-being which is stress, anxiety, and depression that they are experiencing. Besides, selfesteem, competency, autonomy, psychological adjustment of a person could also be improved when a student have peer acceptance and social support from peer (Parker \& Asher, 1993). According to the research of Parker, Rubin, Price, and Rosier in the year 1995 have stated that a person may have higher degree of loneliness and depression when he or she have difficult in developing peer relationship, so developing peer relationship was very important to a youth or young adult.

According to the study of Ueno (2005), it showed that individuals who were integrated into social network at school have better mental health than those who were social excluded by measured the numbers of depressive symptoms. Besides, the analyses of depressive symptoms also have showed that individual who having more friends, fewer depressive symptoms have showed by him or her. In the study by Ueno also have conclude that positive feelings in the peer relationship such as sense of belonging, trust, support, and communication were contributed to the positive psychological well-being. Peer support, peer trust and peer loyalty were particular important predictor variables and significant related to psychological well-being. Hence, development of peer relationship should be encouraged because close peer relationship related to various aspects of psychological well-being.

One of the research on late adolescent or young adult has showed that higher psychological well-being have connected with feeling understood, appreciated and meaningful interaction with friends (Reis, Sheldon, Gable, Roscoe, \& Ryan, 2000). According to Hartup research in year 1996 also reported that closer peer relationship and have meaningful interaction with peer will contributed positively wellbeing to a person. However, feeling depressed and negative self-views of a person will occurred when he or she have peer relationship problem such as peer rejection (Gross, Juvonen, \& Gable, 2002).

Besides, interpersonal theories of depression have state that a person will begin feel low self-worth and low effectiveness on peer relationship when he or she felt depressed (Coyne, 1976). Although the person will try to compensate his self-worth by increasing his or her social contact and sought feeling of belonging among friends, but these actions no only created more tension to the friends and make them diving away from the depress person, it was also influence and give impact 
Hanina Halimatussaidiyah Hamsan; R elationships between academic environment, peer relationship, time management and psychological well-being

on the depressed person (Phillips, 2001). Besides, a study have stated that women were at higher risk experience to depression when compare with man (NolenHoeksema, Susan, 2001).

Some of the studies (Schafer, 1996; Greenberg, 1996; Pfeiffer, 2001; Harajyoti, Dipankar, Lipika, \&Nabanita, 2012) have concluded that there has a significant relationship between stress and college student. Making new friends, changing new friendship or developing new friendship were one of the sources of stress among student and it could be stressful activities to some of the student (Greenberg, 1996). The process of developing new friendship or finding someone who can share something and get support was an important step in the development of student and it was also important source of psychological well-being and social support. New friendship need a period of time to test how much selfdisclose to that person and feel comfortable between each other. This process could be stressful to a person (Pfeiffer, 2001).

\subsection{Relationship between time management and psychological well-being}

Time management was a major issue among university students. It affects how a student view and using the time available to them. Besides, it also affects how they adjust to their academic responsibilities by using time that available for them (Bonhomme, 2007). Product of organizing skills was often defined as time management, but the same processes may not be applied for every people in same pattern or way (Macan, 1996).

Personal application of practical skill effectively in doing and organizing daily activity and responsibilities has included in time management. The needed of time in doing the activity must be able to forecast by a person in order to take advantages of using time effectively (Kelly, 2002). A person who have planning and clearly understanding what so he want to do, what they need to do and so on was a person who can manage their time effectively (Soucie, 1986; Laurie, 2012). Negative aspect of psychological well-being such as stress could be reduced if an individual have good time management by being more in control of their time and being more effective. People who have good time management skill more quality time to relax and enjoy their life (Macan, Shahani, Dipboye\& Phillips, 1990; Jones, 2003).

Four-factor models of time management which were setting goals and priorities, planning and scheduling, perceived control over time, and preference for disorganization related to university 
student have introduced by Macan, Shahani, Dipboye and Phillips in year 1990. Perceive control over time have strongly related to a students' academic and psychological and emotional adjustment. People who have higher in perceive control over time was having higher performance in academic and psychological and emotional adjustment (Britton \&Tesser, 1991; Macan et al., 1990).

Besides, Macan et al. in year 1990 have strongly stated those students who have the ability in perceived control of time have correlated to the lower stress levels. Students who were ability to manage their time successfully and productively such as writing lists, setting goals and so on has felt less stress in their experience of study life. In contrast, if they do not have ability to control their time or have good attitude to time management, they has felt stressed in their life. Moreover, high level of perceive control the time have high level of coping among university of student (Misra\& McKean, 2000). If student have ability in coping themselves with university environment, and problem, he or she will feel happy and less stressful in their university life.

\section{METHODOLOGY}

Research Design was a structure and plan of research in order to provide a credible answer to a problem or research question. The purpose of research design was to recognize the most appropriate way of conducting research. Besides, it also used to identify research variable and the way of variable operate.

The resign design that used in this research was descriptive research. In this present studies, descriptive research was used in order to describe the current state of affairs of the phenomena at the time of the study. Descriptive research was including collect data which can describe the event and organize, express in word, and describe the data (Glass \& Hopkins, 1984). Survey research which studied the characteristics of population through the survey was used in these studies. The basic tools such as questionnaire was used in order to examine relationship between academic environment, peer relationship, time management, and psychological well-being among final year student in Universiti Putra Malaysia, Serdang.

Besides that, this research was going to use correlational research, or also called as relational design. According to Janet Waters, a correlational research was a quantitative method of research in which used to describe the relationship between two or more variables (independent variable and dependent variable). Thus, this research was suitable to use in this 
Hanina Halimatussaidiyah Hamsan; R elationships between academic

environment, peer relationship, time management and psychological well-being

study the correlation between academic environment, peer relationship, time management, and psychological well-being among final year student in Universiti Putra Malaysia, Serdang. The correlation research helps to determine the relationship between academic environment and psychological wellbeing, peer relationship between psychological well-being, as well as time management and psychological well-being.

\subsection{Study Location}

This study was conducted in Universiti Putra Malaysia (UPM), which is locating in Serdang, Selangor. Universiti Putra Malaysia is one of the government universities in Peninsular Malaysia and occupy $2,740.65$ acre. It was formerly known as "UniversitiPertanian Malaysia" or Agricultural University of Malaysia. Universiti Putra Malaysia is a research university which offering undergraduate and post-graduate courses. Currently Universiti Putra Malaysia offers 73 Bachelor's degree programs, 8 Diploma programs, 12 Masters and Doctoral programs. There are 16 Faculties, 17 Colleges, 8 Centers, 6 Institutes, 2 Schools, a University Park and a branch campus in Bintulu, Sarawak. Convenience was the main factor considered for the research location in which I can easily get the respondent.

\subsection{Population and Sample Size}

In this study, the populations were the students who studied at Universiti Putra Malaysia, Serdang, Selangor. The sample was the final year students with eldest category or "Sulung" category that studied at Faculty of Human Ecology, Faculty of Economics and Management, Faculty of Engineering which provided by Academic Department of UPM, Serdang.

\section{RESULT AND ANALYSIS}

\subsection{Respondent Background}

Descriptive statistics was used to analysis the percentage; mean, standard deviation, minimum and maximum value of the variables. There were total of 333 final year students, which had 158 males (47.4\%) and 175 female (52.6\%). There were 10 student $(3.0 \%)$ who aged 22, 86 students (25.8\%) who aged 23, 175 students (52.6\%) who aged 24,40 students (12.0\%) who aged 25,15 students (4.5\%) who aged 26, 6 students (1.8\%) who aged 27 , and 1 student $(0.3 \%)$ who aged 29. The mean of age was 23.96 years old; meanwhile the standard deviation was 0.958 . The minimum age of the students was 22 years old; the maximum age was 29 years old. For the race, it had 92 Malay students or $27.6 \%$. Indian race students were consists of 30 
Al-Fikra: J urnal IImiah Keislaman, Vol. 16, No. 1, J anuari - J uni, 2017 (1 - 27)

people $(9.0 \%)$ and Chinese students

respondents.

were 211 people or $63.4 \%$ as the

Table 1: Final Year Student's Characteristics $(n=333)$

\begin{tabular}{|c|c|c|}
\hline Variable & $\mathrm{N}$ & $\%$ \\
\hline \multicolumn{3}{|l|}{ Age (Years) } \\
\hline 22 & 10 & \\
\hline 23 & 86 & 25.8 \\
\hline 24 & 175 & 52.6 \\
\hline 25 & 40 & 12.0 \\
\hline 26 & 15 & 4.5 \\
\hline 27 & 6 & 1.8 \\
\hline \multirow[t]{5}{*}{29} & 1 & 0.3 \\
\hline & 23.96 & \\
\hline & 0.958 & \\
\hline & 22 & \\
\hline & 29 & \\
\hline \multicolumn{3}{|l|}{ Gender } \\
\hline Male & 158 & 47.4 \\
\hline Female & 175 & 52.6 \\
\hline \multicolumn{3}{|l|}{ Race } \\
\hline Malay & 92 & 27.6 \\
\hline Chinese & 211 & 63.4 \\
\hline Indian & 30 & 9.0 \\
\hline
\end{tabular}

Note. Sd. $=$ Standard deviation, Min. = Minimum, Max. $=$ Maximum

\subsection{Level of Academic Environment}

Level of academic environment was measured by using University Environment Scale (UES). This UES had 14 items in order to measure the perceptions and concern of student to the university environment. Five out of fourteen items were negative statement, which were 1, 4, 5, 11 and 13. The level of perception toward university environment had categorized into 3 ranges, which were low level of perception to academic environment (14-27), moderate level of perception to academic environment (28-41), and high level of perception to academic environment (42-56). Majority students' perception to academic environment was moderate level, which means 265 students or 
Hanina Halimatussaidiyah Hamsan; R elationships between academic environment, peer relationship, time management and psychological well-being

$79.58 \%$ not had too high or not too low perception to university academic environment. There were 3 students $(0.9 \%)$ fall under low perception of academic environment. Students who had high concern of academic environment only had 65 students $(19.52 \%)$, which means out of 10 only had 2 students who had high level of concern about academic environment. The mean for academic environment score was 38.466 whereas the standard deviation was 4.081 . The minimum value for total university environment score was 21 and maximum value was 50 .

Table 2: Academic Environment $(n=333)$

\begin{tabular}{cll}
\hline Level (Score) & $\mathrm{N}$ & $\%$ \\
\hline High (42-56) & 65 & 19.52 \\
Moderate (28-41) & 265 & 79.58 \\
Low (14-27) & 3 & 0.9 \\
Mean & 38.466 & \\
Sd. & 4.081 & \\
Min. & 21 & \\
Max. & 50 &
\end{tabular}

\subsection{Level of Peer Relationship}

Peer relationship was examined by using Index of Peer Relationship (IPR). A total 25 questions were asked in order to measure the severity, degree or magnitude of problem between respondent with peers. The level of peer relationship had categorized into 3 ranges, which were low level of peer relationship (25-74), moderate level of peer relationship (75-124), and high level of peer relationship (125-175). Majority respondents had low level of peer relationship, that means 194 students or $58.26 \%$ didn't had severity or problem with their peers. There were 134 students (40.24\%) fall under moderate level of peer relationship. Students who had high level of peer relationship only had $1.50 \%$ out of total respondents that means they were only 5 students had severity of problem with peer. The mean for peer relationship score was 74.009 whereas the standard deviation was 21.298. The minimum value for total university environment score was 25 and maximum value was 138. 
Table 3: Peer Relationship ( $\mathbf{n = 3 3 3 )}$

\begin{tabular}{cll}
\hline Level (Score) & N & $\%$ \\
\hline High (125-175) & 5 & 1.50 \\
Moderate (75-124) & 134 & 40.24 \\
Low (25-74) & 194 & 58.26 \\
$\quad$ Mean & 74.009 & \\
Sd. & 21.298 & \\
Min. & 25 & \\
Max. & 138 & \\
\hline
\end{tabular}

Note. Sd. = Standard deviation, Min. = Minimum, Max. = Maximum

\subsection{Level of Time Management Behaviour}

There were four subscales under time management, which were setting goals and priorities; planning and scheduling, perceived control over time, preference for disorganization. This section was discussed on the level of these subscales.

\subsubsection{Setting Goals and Priorities}

Setting goal and priorities scale was evaluated the willing of respondent in selecting and prioritizing academic tasks in order to reach their objective. Total level of setting goals and priorities was categorized into 3 ranges, which were low level of setting goals and priorities (1023), moderate level of setting goals and priorities (24-37), and high level of setting goals and priorities (3852 ). Most of the final year students were fall under moderate level of setting goals and priorities which were 262 students $(78.68 \%)$ that mean respondents were not too frequent use of time management skills or too frequent use of time management skills. There were 34 students $(10.21 \%)$ fall under low level of setting goals and priorities. Students had high level of setting goals and priorities only had $11.11 \%$ which means 37 students out of 333 students had good time management skill. The mean for level of setting goals and priorities was 31.342 whereas the standard deviation was 5.302. The minimum value for total university environment score was 19 and maximum value was 43 . 
Hanina Halimatussaidiyah Hamsan; R elationships between academic environment, peer relationship, time management and psychological well-being

Table 4: Setting Goals and Priorities $(n=333)$

\begin{tabular}{cll}
\hline Level (Score) & $\mathrm{N}$ & $\%$ \\
\hline High (38-52) & 37 & 11.11 \\
Moderate (24-37) & 262 & 78.68 \\
Low (10-23) & 34 & 10.21 \\
Mean & 31.342 & \\
Sd. & 5.302 & \\
Min. & 19 & \\
Max. & 43 & \\
\hline
\end{tabular}

Note. Sd. = Standard deviation, Min. = Minimum, Max. = Maximum

\subsubsection{Planning and Scheduling}

Planning and scheduling evaluates the planning and scheduling techniques with effective time management. Total level of planning and scheduling was categorized into 3 ranges, which were low level of planning and scheduling (11-25), moderate level of planning and scheduling (26-40) and high level of planning and scheduling (41-56). Most of the final year student had fall under moderate level of planning and scheduling which were 216 students $(64.87 \%)$, which mean respondents were not too frequent use of time management skills or too frequent use of time management skills. There were 29 students $(8.71 \%)$ fall under low level of planning and scheduling, which means 29 students didn't had good time management skill in this study. Students who had high level of planning and scheduling only had $26.43 \%$ which means 88 students out of 333 students had good time management skill. The mean for level of planning and scheduling was 35.321 whereas the standard deviation was 6.918. The minimum value for total university environment score was 16 and maximum value was 48 .

Table 5: Planning and Scheduling $(n=333)$

\begin{tabular}{cll}
\hline Level (Score) & $\mathrm{N}$ & $\%$ \\
\hline High (41-56) & 88 & 26.43 \\
Moderate (26-40) & 216 & 64.87 \\
Low (11-25) & 29 & 8.71 \\
Mean & 35.321 & \\
Sd. & 6.918 & \\
Min. & 16 & \\
Max. & 48 &
\end{tabular}




\subsubsection{Perceived Control over Time}

Perceived control over time was used to do an evaluation the degree of respondent perceived his or her effectively control of time. High score means that respondent dedicating a lot of time in secondary tasks and lacks of sensation in control time. Level of perceived control over time was categorized into 3 ranges, which were low level of perceived control over time (511), moderate level of perceived control over time (12-18) and high level of perceived control over time (19-26). Most of the final year student fall under moderate level of perceived control over time which were 242 students (72.67\%), which mean respondents were not too dedicating or too dedicating lot of time in secondary tasks and lacks of sensation in control time. There were 53 students (15.92\%) fall under low level of perceived control over time. They were $11.41 \%$ of student fall under high level of perceived control over time, which means 38 students lack of sensation in control the time or taking too many work and responsibility. The mean for level of perceived control over time was 15.126 whereas the standard deviation was 3.230 . The minimum value for total university environment score was 17 and maximum value was 22.

Table 6: Perceived Control over Time $(n=333)$

\begin{tabular}{lll}
\hline Level (Score) & $\mathrm{N}$ & $\%$ \\
\hline High (19-26) & 38 & 11.41 \\
Moderate (12-18) & 242 & 72.67 \\
Low (5-11) & 53 & 15.92 \\
Mean & 15.126 & \\
$\quad$ Sd. & 3.230 & \\
Min. & 17 & \\
$\quad$ Max. & 22 & \\
\hline
\end{tabular}

Note. Sd. = Standard deviation, Min. = Minimum, Max. = Maximum

\subsubsection{Preference Disorganization}

Preference for disorganization was referred the way respondent organizing his or her tasks and the degree of which his or her maintain a study environment. High score on this factor represent the development of activities without prior structuring and planning or maintaining a study setting. Total for level of preference for disorganization was categorized into 3 ranges, which were low level of preference for disorganization (8$18)$, moderate level of preference for disorganization (19-29) and high level of preference for disorganization (30-41). Most of the final year students fall under moderate level of preference for disorganization which were 229 students $(68.77 \%)$. There were 48 
Hanina Halimatussaidiyah Hamsan; R elationships between academic environment, peer relationship, time management and psychological well-being

students $(14.41 \%)$ fall under low level of preference for disorganization. They were $16.82 \%$ of student fall under high level of preference for disorganization, which means 56 students out of 333 students developed their activities without prior structuring and planning. The mean for level of preference for disorganization was 24.165 whereas the standard deviation was 4.986 . The minimum value for total university environment score was 13 and maximum value was 22 .

Table 7: Preference for Disorganization $(n=333)$

\begin{tabular}{lll}
\hline Variable & $\mathrm{N}$ & $\%$ \\
\hline High (30-41) & 56 & 16.82 \\
Moderate (19-29) & 229 & 68.77 \\
Low (8-18) & 48 & 14.41 \\
$\quad$ Mean & 24.165 & \\
$\quad$ Sd. & 4.986 & \\
Min. & 13 & \\
$\quad$ Max. & 35 & \\
\hline
\end{tabular}

Note. Sd. $=$ Standard deviation, Min. = Minimum, Max. = Maximum

\subsubsection{Overall Score of Time Management Behavior}

Time Management Behavior Scale was used to measured time management behavior and attitude of respondent. Total level of time management behaviour was categorized into 3 ranges, which were low level of time management behaviour (55-84), moderate level of time management behaviour (85114 ) and high level of time management behaviour (115-145). Most of the final year students were fall under moderate level of time management behaviour which was
176 students $(52.85 \%)$. There were 49 students (14.72\%) fall under low level of time management behaviour. They were $32.43 \%$ of student fall under high level of preference for disorganization, which means 108 students out of 333 students more frequent use of time management and represented they have good management skills. The mean for level of preference for disorganization was 105.955 whereas the standard deviation was 18.399. The minimum value for total university environment score was 59 and maximum value was 145 . 
Table 8: Overall Time Management Behaviour $(n=333)$

\begin{tabular}{lll}
\hline Variable & $\mathrm{N}$ & $\%$ \\
\hline High (115-145) & 108 & 32.43 \\
Moderate (85-114) & 176 & 52.85 \\
Low (55-84) & 49 & 14.72 \\
$\quad$ Mean & 105.955 & \\
Sd. & 18.399 & \\
$\quad$ Min. & 59 & \\
Max. & 145 & \\
\hline Note. Sd. = Standard deviation, Min. = Minimum, Max. = Maximum
\end{tabular}

\subsection{Level of Psychological Well-being}

There were three subscales under psychological well-being, which were depression, anxiety and stress. This section was discussed on the level of these subscales.

\subsubsection{Level of Depression}

Total level of depression was categorized into 5 ranges, which were normal depression level (0-4), mild depression level (5-6), moderate depression level (7-10), severe depression level (11-13) and extremely severe depression level (more than 14). Most of the final year students were fall under moderate depression level which was 93 students (27.93\%). There were 90 students $(27.03 \%)$ fall under normal depression level, 52 students or $15.62 \%$ fall under mild depression level, 45 students $(13.51 \%)$ fall under severe depression level and 53 students $(15.92 \%)$ under extremely severe depression level. The mean for depression level was 8.096 whereas the standard deviation was 4.757. The minimum value for total depression level was 0 and maximum total of depression level was 19.

Table 9: level of Depression $(n=333)$

\begin{tabular}{lll}
\hline Level (Score) & N & $\%$ \\
\hline Normal (0-4) & 90 & 27.03 \\
Mild (5-6) & 52 & 15.62 \\
Moderate (7-10) & 93 & 27.93 \\
Severe $(11-13)$ & 45 & 13.51 \\
Extremely Severe (14+) & 53 & 15.92 \\
. Mean $\quad 8.096$ & \\
$\quad$ Sd. & 4.757 & \\
$\quad$ Min. & 0 & \\
$\quad$ Max. & 19 & \\
\hline
\end{tabular}

Note. Sd. $=$ Standard deviation, Min. = Minimum, Max. = Maximum 
Hanina Halimatussaidiyah Hamsan; Relationships between academic environment, peer relationship, time management and psychological well-being

\subsubsection{Level of Anxiety}

Total level of anxiety was categorized into 5 ranges, which were normal anxiety level (0-3), mild anxiety level (4-5), moderate anxiety level (6-7), severe anxiety level (8-9) and extremely severe anxiety level (more than 10). Half of the final year students were fall under extremely severe anxiety level in this study which was 164 students $(49.25 \%)$, which means most of student suffered in negative emotional states. There were only 25 students $(7.51 \%)$ falls under normal anxiety level, 30 students or $9.01 \%$ fall under mild depression level, 66 students (19.82\%) fall under moderate anxiety level and 48 students $(14.41 \%)$ under severe anxiety level. The mean for anxiety level was 9.444 whereas the standard deviation was 4.221 . The minimum value for total anxiety level was 0 and maximum total of anxiety level was 20 .

Table 10: Level of Anxiety $(n=333)$

\begin{tabular}{lll}
\hline Level (Score) & $\mathrm{N}$ & $\%$ \\
\hline Normal (0-3) & 25 & 7.51 \\
Mild (4-5) & 30 & 9.01 \\
Moderate (6-7) & 66 & 19.82 \\
Severe (8-9) & 48 & 14.41 \\
Extremely Severe (10+) & 164 & 49.25 \\
. Mean $\quad 9.444$ & \\
$\quad$ Sd. & 4.221 & \\
$\quad$ Min. & 0 & \\
\hline Max. & 20 & \\
\hline
\end{tabular}

Note. Sd. $=$ Standard deviation, Min. = Minimum, Max. = Maximum

\subsubsection{Level of Stress}

Total level of stress was categorized into 5 ranges, which were normal stress level (0-7), mild stress level (8-9), moderate stress level (10-12), severe stress level (13-16) and extremely severe stress level (more than 17). Most of the final year student fall under normal stress level which was $36.94 \%$, which means 123 out of 333 students suffered in positive emotional states. There were 52 students $(15.62 \%)$ fall under mild stress level, 79 students or $23.72 \%$ fall under moderate stress level, 59 students $(17.71 \%)$ fall under severe stress level. They were only 17.71 $\%$ fall under extremely severe stress level, which means 20 students out of 333 students were suffered in negative emotional states. The mean for stress level was 9.300 whereas the standard deviation was 4.195 . The minimum value for total anxiety level was 0 and maximum total of anxiety level was 20. 
Table 11: Level of Stress $(n=333)$

\begin{tabular}{lll}
\hline Level (Score) & $\mathrm{N}$ & $\%$ \\
\hline Normal (0-7) & 123 & 36.94 \\
Mild (8-9) & 52 & 15.62 \\
Moderate (10-12) & 79 & 23.72 \\
Severe (13-16) & 59 & 17.71 \\
Extremely Severe (17+) & 20 & 6.01 \\
$\quad$ Mean & 9.300 & \\
$\quad$ Sd. & 4.195 & \\
$\quad$ Min. & 0 & \\
\hline
\end{tabular}

Note. Sd. $=$ Standard deviation, Min. = Minimum, Max. = Maximum

\section{CONCLUSION}

The purpose of this research was to determine the relationships of academic environment, peer relationship, time management, and psychological well-being among final year student in Universiti Putra Malaysia. Three faculty final year student were selected to be respondent. A total of 350 questionnaires were distributed to the students. However, only 333 questionnaires had returned.

University Environment Scale (UES) developed by Gloria and Karpius (1996) was adopted as the instrument to measure perception and concern of the student to the university environment. Index of peer relationship (IPR) developed by Walter W. Hudson (1992) was used to assess university final year students' perception of the severity, degree or magnitude of a problem with peers. Time Management BehaviourScale (Macan, 1990) was used to measure time management behaviour and attitude of a student. Lastly, Depression Anxiety Stress
Scale 21 (DASS21) developed by Lovibond and Lovibond's (1995) was assessed three negative emotional states which are depression, anxiety and stress of student.

Descriptive analysis was used to identify the respondents' individual characteristics, the level of academic environment, peer relationship, time management of final year student in term of frequency, percentage, mean, standard deviation, minimum, and maximum. Pearson correlation was used to determine the relationship between the independent variables (academic environment, peer relationship, time management and dependent variable (psychological well-being). Lastly, multiple regression analysis was used to determine which independent variable significantly predict for psychological well-being among final year student.

\section{REFERENCES}

American Academy of Child and Adolescent Psychiatry 
Hanina Halimatussaidiyah Hamsan; Relationships between academic environment, peer relationship, time management and psychological well-being

(2012). Peer pressure. Facts for families, (104).

American College Health Association. (2012).

American College Health Association- National

College Health Assessment II: Undergraduate Reference Group Executive Summary Spring 2012. Hanover, MD: American College Health Association.

Antony, M. M., Bieling, P. J., Cox, B. J., Enns, M. W., \&Swinson, R. P. (1998). Psychometric properties of the 42-item and 21-item versions of the Depression Anxiety Stress Scales in clinical groups and a community sample. Psychological

Assessment, 10(2), 176181.

Blatchford, P., Bassett, P., Goldstein, H., \& Martin, C. (2003). Are class size differences related to pupil's educational progress and classroom processed? British Educational Research J ournal, 29(5), 709-714.

Boey, K.W., Chan, K.B. \&Ko, Y.C.(1998). Stress coping strategy and psychological well-being of Nurses: The Singapore Experience. Chinese Journal of Mental Health, 11, 1-20.

Bolger, K. E., Patterson, C. J., \&Kupersmidt, J. B. (1998). Peer relationships and selfesteem among children who have been maltreated. Child Development, 69, 11711197.
BonhommeGA .(2007). The time management skills of at-risk African American college students: practices, experience, and context (Dissertation). Lafayette, LA, USA: Faculty of the University of Louisiana at Lafayette, 483.

Glass, G.V., \& Hopkins, K.D. (1984). Statistical methods in education and psychology: Englewood Cliffs, NJ: Prentice Hall.

Gloria, A. M., \&Kurpius, S. E. R. (1996). The validation of the cultural congruity scale and the University Environment Scale with Chicano/a students. Hispanic J ournal of Behavioral ciences, 18, 533549.

Grolnick, W. S., \& Ryan, R. M. (1987). Autonomy in children's learning: An experimental and individual difference investigation. Journal of Personality and Social Psychology, 52, 890898.

Greenberg, J. S. (1996). Comprehensive stress management (5th ed.). Chicago: Brown \& Benchmark.

Gross, M.K. (2009). The effects of class size in elementary physical education: An examination of study activity level, class management and teacher attitude. Auburn University, 1-136.

Hartup, W. W. (1996). The company they keep: Friendships and their developmental 
significance.

Development, 67, 1-13.

Hudson, W. W. (1993). Index peer relationship.

WALMYR

Publishing Company.

Israel, G.D. (2009). Determining sample size.University of Florida.PEOD 6.1-5.

Janet Waters. (2012). Correlational Research Guidelines. British Columbia Canada: Capilano University.

Kelly, W. E. (2002). No time to worry: the relationship between worry, time structure, and time management. Personality and Individual Differences, 35, 1119-1126.

Larson, R., \& Richards, M. H. (1991). Daily companionship in late childhood and early adolescence: Changing developmental contexts. Child Development, 62, 284-300.

Laurie-Ann M. Hellsten (2012). What Do We Know About Time Management? A Review of the Literature and a Psychometric Critique of Instruments Assessing Time Management.Time Management. University of Saskatchewan, Canada.

Lazarus, R. S., \&Folkman, S. (1984). Stress, Appraisal and Coping. New York: Springer.

Lovibond, S. H., \&Lovibond, P. F. (1995). Manual for the Depression, Anxiety and Stress Scales (2nd ed.). Sydney, Australia: Psychology Foundation.

Macan, T. H. (1994). Time management: Test of a process model, Journal of
Applied Psychology, 79(3), 381-391.

Macan, T. H., Shahani, C., Dipboye, R. L., \& Phillips, A. P. (1990). College students time management: Correlations with academic performance and stress. J ournal of Educational Psychology, 82, 760-768.

Macan, T. H. (1996). Timemanagement training: Effects on time behaviors, attitudes, and job performance. Journal of Psychology, 130, 229-236.

Marcus, M., M. Yasamy, T., Ommeren, M. V., Chisholm, D., \&Saxena, S. (2012). Depression: A global crisis. World Health Organization, 1-30

Mazumdar, H., Gogoi, D., Buragohain, L., \&Haloi, $\mathrm{N}$. (2012).A comparative study on $s$ tress and its contributing factors among the Graduate and Postgraduate students. Pelagia Research Library, 3 (1), 399-406

Misra, R., \& McKean, M. (2000).College students' academic stress and its relation to their anxiety, time management, and leisure satisfaction.American J ournal of Health Studies, 16, 41-51.

Moos, R. (2003). Social contexts: transcending their power and their fragility. American Journal of Community Psychology, 31(1-2), 1-13.

Moos, R. (2003). The Social Climate Scales: A User's Guide (3rd ed.). Redwood 
Hanina Halimatussaidiyah Hamsan; R elationships between academic environment, peer relationship, time management and psychological well-being

City, CA: Mind Garden, Inc.

Nolen-Hoeksema,\& Susan. (2001). Gender Differences in Depression.Current

Directions in Psychological Science, 10 (5): 173-176.

Nykolas. (2012). How do students define 'character'?.CNN's Schools of Thought. Retrieved 20 November 2012 from http://schoolsofthought.blog sw.cnn.com/2012/ 05/28/how-do-studentsdefine-character/

Parker, J. G., \& Asher, S. R.. (1993). Friendship and friendship quality in middle childhood: Links with peer group acceptance and feelings of loneliness and social dissatisfaction.

Developmental Psychology, 29, 611-621.

Paul Ramsden. (1979). Student learning and perceptions of the academic environment. Higher Education. 8(4), 411427.

Pfeiffer, D. (2001). Academic and environmental stress among undergraduate and graduate college student: A literature review. University of Wisconsin-Stout, 1-29

Ryan, R.M. \&Deci, E.L. (2001). On happiness and human potentials: a review of research on hedonic and eudaimonic well-being. Annual Review Psychology, 52, 141-166.

Ryan, R. M., \&Grolnick, W. S. (1986). Origins and pawns in the classroom: Self-report and projective assessments of individual differences in children's perceptions.

J ournal of Personality and Social P sychology, 50, 550558.

Ryan, R. M., Stiller, J. D., \& Lynch, J. H. (1994). Representations of relationships to teachers, parents, and friends as predictors of academic motivation and self- esteem. Journal of Early Adolescence, 14, 226249.

Ryff, C.D. \& Singer, B. (1998).The contours of positive human health. Psychological Inquiry, 9, 1-28. Santiago, C. (2008). Philippines: Country gender profile. Retrieved Oct. 18, 2012 from

http://www.jica.go.jp/activitie s/issue/gender/pdf/j03. pdf

Ryzin, M.j.V, Gravely, A.A. \&Roserth.c.j.(2009).

Autonomy, belongingness, and engagement in school as contributors to adolescent psychological well-being. Journal Youth Adolescence, 8, 1-12

Sayner B. (2006). Stress level of university student. Istanbul Commerce University J Sci. 5, 23-34.

Seifert T.A. (2005). The Ryff Scales of psychological well-being.University of Lowa. Spring 2005.

Smith, C. (2008). The impact of obesity on the psychological well-being of the adolescent learner. University of South Africa, 1115. 
Al-Fikra: J urnal Ilmiah Keislaman, Vol. 16, No. 1, J anuari - J uni, 2017 (1 - 27)

Soucie, D. (1986). Proper management of your time.CAHPER J ournal, 52, (2), 36.

Stanton-Salazar, $\mathrm{R}$ \&Spina, $\mathrm{S}$ 2005, Adolescent peer networks as a context for social and emotional Support, Youth and Society, 36(4), p. 379.

Stevenson, A \& Harper S. (2006). Workplace stress and the student learning experience, Qual. Assur. Educ., 14(2): 167-178.

Student.(n.d.).Collins English Dictionary-Complete \& Unabridged 10th Edition. Retrieved 14 November, 2012, from Dictionary.com website.http://dictonary. reference.com/browse/stude $\mathrm{nt}$

Williamson, J. \& Robinson, M. (2006).Phychosocial interventions, or integrated programming for well-being, Intervention: The International Journal of Mental Health, Psychosocial Work and Counseling in Areas of Armed Conflict, 4(1), 425.
Wissing, M.P. \& Van Eeden, C. (2003) Empirical clarification of the natural of psychological wellbeing.South African Journal of Psychology, 32(1): 32-44.

Wong, S. Y. \&Lua, P. L. (2011). Anxiety and depressive symptoms among Communities in the East Coast of Peninsular Malaysia: A rural exploration. Malaysia: MJP Online Early, Retrieved November.11, 2012 from http://www.mjpsychiatry.org/ index.php/mjp/article/viewFil e/143/119

World Health Organization.(2012). Depression.Retrieved November 20, 2012.from http://www.who.int/mediace ntre/factsheets/fs369/en/ind ex.html

Zalquett, C. (2005). Principals' perceptions of elementary school counselors' roles and functions. Professional School Counseling, 8(5), 451-457. Retrieved from http://www.schoolcounselor. org/content. asp? contentid=2 35 